\title{
UNA APROXIMACIÓN AL ARTE MUDÉJAR *
}

\section{RAFAel Cómez}

El propósito del presente artículo es discutir la existencia de un estilo mudéjar. Evidentemente, no dudamos de la existencia de un arte mudéjar pero debemos plantearnos la cuestión de si este arte constituye también, del mismo modo, un estilo. La afirmación del conservador y dogmático don Marcelino Menéndez y Pelayo: "(mudéjar), el único tipo de construcción peculiarmente español de que podamos envanecernos", ${ }^{1}$ nos induce a considerar de nuevo la definición de mudéjar como una manifestación de tendencia nacionalista, algo que con frecuencia nos conduce a equivocadas y etróneas actitudes.

De hecho, sospechamos que la definición de estilo mudéjar está relacionada con la especial situación de la "generación del 98", la segunda edad de oro de las letras españolas, cuando la pérdida de las últimas colonias españolas en la guerra con los Estados Unidos de Norteamérica forzó a los eruditos y escritores españoles a buscar las causas de la caída del imperio español $y$, sobre todo, a indagar sobre la verdadera esencia de España. Esta tendencia a considerar la cultura española como muy diferente a otras se tradujo en un peculiar sentimiento o "casticismo" -espíritu de casta o pura raza, según Unamuno--, ${ }^{2}$ quien años más

* El presente artículo resume la ponencia titulada Is there a Mudéjar Art?, presentada en el Medieval Art Forum de la Universidad de Columbia en New York (septiembre de 1981) y la conferencia Mudéjar Art, a New Approach, pronunciada en el Departamento de Arte y Arqueología de la Universidad de Princeton (noviembre de 1981). En esencia, el texto es el mismo correspondiente a la última conferencia, salvo la adición de las notas pertinentes. Este estudio forma parte de un trabajo de investigación más amplio, que publicatemos próximamente, y fue realizado en el Departamento de Arte y Arqueología de la Universidad de Princeton durante el curso 1980-81, gracias a una beca Fullbright del Comité Conjunto Hispano-Norteamericano para Asuntos Educativos y Culturales. El autor agradece a dicha institución la ayuda concedida y asimismo expresa su gratitud a la profesora Jerrilynn D. Dodds por la corrección del texto original en inglés.

1 Apud Leopoldo Torrés Balbás, Arte Almohade, nazarí y mudejar, "Ats Hispaniae", Iv, Madrid, 1949, pp. 238-39.

2 Miguel de Unamuno, En torno al casticismo, 9a ed, Col. Austral, Madrid, 1979, p. 59: "Tstos hombres tienen un alma viva y en ella el alma de sus antepasados, adormecida tal vez, soterrada bajo capas sobrepuestas, pero viva siempre. En muchos, en los que han recibido alguna cultura sobre todo, los rasgos de la casta están alterados, pero están allí." Al mencionar el alma de los antepasados, Unamuno parece anticiparse a la noción de "inconsciente colectivo" enunciada por Jung (Vid C. G. Jung, Teoria del psicoanálisis, Barcelona, 1968). 
tarde sería el portaestandarte del "africanismo" frente al "europeísmo" del filósofo Ortega y Gasset.

Tras la sospecha de que el estilo mudéjar haya sido la expresión de un mítico carácter nacional, ${ }^{3}$ debemos examinar el arte mudéjar para el que todavía no ha sido propuesta una clara definición.

Antes que nada, ¿qué significa mudéjar? La palabra mudéjar deriva de la voz árabe "muddayan" que significa sometido. Por consiguiente, arte mudéjar es aquel arte propio de los musulmanes sometidos que viven bajo gobierno cristiano. En otras palabras, el arte mudéjar representa la transferencia del arte islámico a las estructuras cristianas, un interesante fenómeno de transculturación en el que podemos contem. plar la coexistencia de las formas islámicas y cristianas juntas, hermanadas; en particular el arte islámico y el arte gótico.

¿Cuándo comienza esta particular asimilación? ¿Cómo acontece? El arte mudéjar tiene sus inicios después de la reconquista de las principales ciudades cristianas: Toledo en 1085 y Zaragoza en 1188. Según la división que Menéndez Pidal ${ }^{4}$ hizo de la Reconquista: 19) Repoblación (hasta el año 1002); 29) Poder económico y político (siglo xI) ; 39) Conquista militar (siglo xIII), el arte mudéjar ocupa el periodo más largo de la Reconquista. El primer periodo o repoblación está dominado por el arte mozárabe. Los mozárabes, al contrario que los mudéjares, eran los cristianos que vivian bajo gobierno musulmán y quienes después de ser perseguidos por los musulmanes, emigraron del sur al norte de España, consîruyendo importantes monasterios en Castilla y León. De cualquier modo, es claro que esta división es sólo relativa y no existe realmente una separación tajante entre tales periodos. No obstante, podemos reconocer que el arte mudéjar goza de una vida más larga que el arte mozárabe.

Los comiezos del arte mudéjar no son absolutamente claros y, a veces, aparecen confundidos con el arte mozárabe. Este es el caso de Toledo, como ha advertido Pavón Maldonado. ${ }^{5}$ La fusión del arte islámico y del arte cristiano es evidente en Córdoba y Sevilla, donde el arte mudéjar se desarrolla desde fines del siglo xuı. Así pues, podemos admitir una creciente progresión del arte mudéjar desde los tiempos de la conquista

3 En este sentido vid el estupendo ensayo de Julio Caro Baroja, El mito del carácter nacional. Meditaciones a contrapelo, Madrid, 1970.

4 Apud José Antonio Maravall, El concepto de España en la Edad Media, Madrid, 1954 , p. 253.

5 Basilio Pavón Maldonado, Arte toledano: islámico y mudéjar, Instituto Hispanoárabe de Cultura, Madrid, 1973, p. 59. 
de Toledo (año 1085) por Alfonso VI de Castilla hasta la construcción del Alcázar de Sevilla bajo Pedro I (año 1352). Después de la construcción del Alcázar de Sevilla, cierta especie de moda asaita a los aristócratas castellanos quienes gustan de edificar castillos y palacios mudéjares durante los siglos XIv y xv.

¿Qué caracteriza al arte mudéjar? Generalmente, los principales rasgos del arte mudéjar se refieren al estilo islámico en el exterior del edificio, aun cuando el interior sea de estilo cristiano, por ejemplo, en las iglesias parroquiales; por otra parte, las torres se destacan sobre los edificios, recordando, a veces, la silueta del alminar musulmán sobre la mezquita. Otras veces, el interior en los palacios recuerda el espacio de la arquitectura islámica, con mucha frecuencia el de la Alhambra de Granada. Un gusto especial por la decoración de los muros en edificios civiles y religiosos puede ser considerado otro particular rasgo del arte mudéjar.

Los materiales son, como en el arte islámico, frágiles y perecederos: ladrillo, madera y yeso, suficientemente flexibles para realizar la "lacería" (labor de entrelazo) y la "mukarna" (bóveda de estalactitas). Los "azulejos" (pintados con diseños en color antes de pasarlos al fuego) componen el elemento más usual en la decoración de la parte inferior del muro, dejando la parte media y superior para la decoración en yeso. Todo queda sometido al modelo de diseño geométrico que cubre la mayor parte del muro y que produce un ritmo de elementos que es claramente islámico.

Sin embargo, esto no indica necesariamente la existencia de un estilo puesto que ni las formas, ni los elementos, ni las cualidades de la decoración son nuevas. Todas ellas recuerdan el arte islámico y son propiamente islámicas pero bajo mecenazgo cristiano. Además, la mayoría de las veces la presencia de artistas mudéjares sólo se puede constatar en la decoración del edificio. La tradicional planta basilical cristiana de tres naves se mantiene, y sólo ocasionalmente alguna capilla funeraria semejante a la "qubba" almohade se añade a las naves laterales de la iglesia. La relación entre el estilo almohade y el gótico está claramente definida en las iglesias parroquiales de Sevilla donde ábsides y portadas son góticas, mientras que la torre y los muros ostentan decoración islámica. En este sentido, la separación de estilos es clara, estableciéndose una jerarquía en favor del gótico en la portada y en el ábside de la iglesia, aunque la torre adopte la tipología del alminar.

Si consideramos la historia del término mudéjar, nos damos cuenta que al principio fue confundido con el término mozárabe, término que 
en su tiempo se usó para denominar cualquier edificio cristiano que ostentase rasgos islámicos. ${ }^{6}$ Amador de los Ríos fue el primero en usar correctamente el término en su discurso para la Real Academia de Bellas Artes de San Fernando de Madrid en 1859. En esta exquisita pieza de romántica oratoria encontramos la raiz de esta actitud que enaltece a la "raza" mudéjar como una parte importante de la grandeza española. No obstante, Amador de los Ríos no define el arte mudéjar aun cuando lo denomina estilo "singular, propio y característico de la civilización espanola" defendiéndolo como parte del espíritu nacional. ? Incluso llega

6 Resulia evidente la confusión y hasta cierto punto razonable, ya que en un princípio sólo se consideraion los elementos árabes y no estaba aún consagrado el término mudéjar, creación propia de los exuditos y arqueólogos de la segunda mitad del siglo xIx. Así pues, la no distinción entre los dos grupos étnicos, mozárabe y mudéjar, aparece claramente en la obra de Eugenio Llaguno y Amirola, Noticia de los arquitectos y arquitectura desde su restauración, por D. Eugenio Llaguno y Amirola, ilustradas y acrecentadas con notas, adiciones y documentos, por D. Juan Agustin Ceán Bermúdez, Madrid, 1829, I, p. xxir: "A los moros sucedieron en España en este género de arquitectura los cristianos mozárabes, que la aprendieron de ellos; y como eran de distinta religión variaron los adornos, y poco a poco alteraron la arquitectura árabe. Desecharon los arcos de herradura, pero mantuvieron los puntiagudos; adelgazaron más las columinas, las prolongaron, las agruparon y las arrimaron a las paredes; agran. daron los azulejos en forma cuadrada; los realzaron con moldes y les dieron color de bronce; añadieron en los techos unas vigas o alfardas, con que atravesaban los edifi. cios por dentro y las colocaban en Ios frisos superiores, donde empezaba a elevarse el alfarge o artesonado. Constaban estas vigas de muchas piezas pequeñas, bien unidas y ensambladas, formando mil graciosas figuras geométricas en los huecos. Duró mucho tiempo en España este modo de trabajar los techos y alfardas, pues Diego López de Arenas publicó en Sevilla el año de 1632 un compendio de carpintería, en que daba reglas y medidas para ejecutarlos, refiriendo los que había trabajado de esta clase, y que todavía subsisten en aquella ciudad."

7 La primera edición del famoso discurso de José Amador de los Ríos fue un fascículo titulado Discursos leidos ante la Real Academia de Nobles Artes de San Fer. nando, en la recepción pública de Don José Amador de los Rios, Madrid, 1859, que se repartió entre los asistentes al acto $\mathrm{Su}$ autor corrigió la redacción del discurso y lo reeditó trece años más tarde en el primer tomo de Discursos leidos en las recepciones y actos públicos celebrados por la Real Academia de las Tres Nobles Artes de San Fiernando desde 19 de junio de 1859, Madrid, 1872. Nosotros hemos seguido la última reedición crítica, J. Amador de los Ríos, El estilo mudéjar en arquitectura, 'Introducción, edición y notas de Pierre Guenoun, Centre de Recherches de l'Institut d'Études Hispaniques, Paris, 1965, p. 51 . Desde un principio la denominación de "estilo mudéjar" resultó polémica ya que Manuel de Assas se arrogó la creación del término acusando de plagio a Amador de los Ríos (vid. Manuel de Assas y de Ereño, "Portada de una casa de Toledo que se conserva en el Museo Arqueológico Nacional", Museo Español de Antigïiedades, 1I, Madrid, 1874, pp. 133-57). En cambio, la denominación "estilo mudéjar" tuvo defensores como José Fernández Giménez, "De la arquitectura cristiano-mahometana", El arte en España, I (1862), pp. 11-16, 21-23, 274-280 y detractores como Pedro de Madrazo, "De los estilos en las artes", La ilustración española 
a afirmar que no tiene paralelo en otras naciones meridionales, olvidándose, por ejemplo, del arte sículo-normando. ${ }^{8}$ Así pues, el arte mudéjar es tratado con la ideología usual del siglo xIx integrar al carácter nacional algo que aparece como extraño o diferente; al combinar lo exótico con los estilos tradicionalmente conocidos (románico-mudéjar, gótico-mudéjar, renacimiento-mudéjar) se convierten en algo distinguido y nacional, rechazando por tanto el peligro de heterodoxia y produciendo una feliz tranquilidad de conciencia nacional.

Lampérez, en 1908, dice que "la arquitectura mudéjar es la hecha para el uso de los cristianos, mezclando elementos del arte mahometano y del cristiano, en dosis mayores o menores". ${ }^{9}$ Aunque es obra musulmana, reconoce que, a veces, es obra cristiana tratada a la manera musulmana, refiriéndose sistemáticamente a la doctrina de Amador de los Ríos.

Gómez-Moreno en su famoso libro Iglesias mozárabes (1919), alaba el genio de la raza y lo castizo. Sostiene que el gran ciclo de "nuestro arte nacional" comienza con la conquista de Toledo (1085) y lo conduce al "mudejarismo"; el arte mudéjar, por consiguiente, es un complemento del arte mozárabe, aunque para él los límites entre uno y otro arte no son claros. "Da carácter a lo español." Finalmente encontramos un intento de definición cuando dice: "es unas veces moruno puro, y otras no conserva de tal sino la envoltura, la técnica o el ritmo, injertos en un organismo cristiano y septentrional, le falta alma, poesia." 10

La influencia de Unamuno sobre Gómez-Moreno es obvia. El gran granadino, mentor de una importante generación de historiadores del arte español que se adscribirían al mismo casticismo de su maestro.

La historiadora americana Georgiana King, en su libro Mudéjar, dedicado a su amigo Gómez Moreno, después de describir los materiales realizados con una imaginación diferente, no europea, dice que "difícilmente puede ser definido con más exactitud pero, no obstante, puede ser reconocido", ${ }^{11}$ Evidentemente, el arte mudéjar puede ser reconocido

y americana, 1888, 1ํ, pp. 262-63, 295-98. Curiosamente Pedro de Madrazo había sido el académico encargado de contestar con el discurso reglamentario a Amador de los Ríos en su recepción pública de la Academia de San Fernando, pero acabaría abjurando del término y negándolo en la publicación antes citada.

8 José Amador de los Ríos, op cit., p. 7; pero en ningún momento define el "estilo mudéjar". que siempre va a remolque del gótico o del renacimiento.

9 Vicente Lampérez y Romea, Historia de la arquitectura cristiana española en la Edad Media, III, Madrid, 1908, p. 483.

10 Manuel Gómez Moreno, Iglesias mozárabes, Madrid, 1919, p. 2.

11 Georgiana Goddard King, Mudéjar, Filadelfia, 1927, pp. 1-2. Entre los historiadores extranjeros que aceptaron la denominación "estilo mudéjar" encontramos a Elie 
pero por un experto, por alguien que se haya dedicado a su estudio; porque cualquiera puede confundirlo con el arte islámico, como de hecho nos ha ocurrido, a veces, cuando hemos mostrado fotografías de arte mudéjar fuera de España. Si el arte mudéjar es una parte del arte del Islam, como afirma King, ${ }^{12}$ es por consiguiente arte islámico pero no cristiano.

El arquitecto e historiador Leopoldo Torres Balbás, que consagró su vida al estudio de la arquitectura medieval española, acepta el término mudéjar para las obras realizadas en territorio cristiano bajo influencia islámica, ${ }^{13}$ concluyendo que a falta de otro término más exacto, éste parece conveniente. Torres Balbás vio la falta de unidad y la calidad fragmentaria del arte mudéjar como atribuible a la gran variedad de artes foráneas que llegan a la Península Ibérica, más que a aquellas de inspiración oriental Sus cualidades lo hacen un arte "profundamente hispánico", "nuestro pueblo vio en él su expresión más genuina, su lenguaje tradicional". ${ }^{14}$ Torres Balbás, pues, resulta apasionado pero incapaz de definir el arte mudéjar.

Finalmente, su discípulo Fernando Chueca Goitia confiesa que el mudéjar "no es propiamente un estilo". ${ }^{15}$ Consiste en cierta actitud de la sociedad española traducida en el arte; no es un estilo formal pues un estilo es siempre el resultado de una tendencia al clasicismo, y el

Lambert, "Liat mudejar", Gazette de Beatix"Atits, 75 (1993), pp. 17-93: "csitito un poco híbrido". Asimismo Enst Kühnel, Islamic Art and Architecture, 2a ed., Cornell University Press (1966), p. 138: "El estilo mudéjar comprende menos un limitado periodo que un movimiento que aparece aquí y allá, pero que mantiene una cierta continuidad de desarrollo". Del mismo modo F. Spalding, Mudejar Omament in Manuscripts, New York, 1953, p. 22: "España es la fuente de manuscritos que combinan la fortma de versales con el distintivo género de elaboración conocido como estilo mudéjar."

12 Georgiana Goddard King, op. cit, pp. 1-2.

13 Leopoldo Torres Balbás, op. cit, p. 238. Esta actitud de aceptar el término ante la falta de otro tiene su antecedente en José Gestoso, Ensayo de un diccionario de los artifices que florecieron en Sevilla desde el siglo XIII al XVIII, Sevilla, 1899, I, p. XIII: "Las especiales circunstancias por las que atravesó la sociedad española de los siglos medios y de los primeros de la Edad Moderna, hicieron brotar en nuestra patria un estilo artístico genuinamente español, formado de la fusión de los elementos cristianos y sarracenos, que, a falta de otra más apropiada denominación, distinguese actualmente con la de mudéjar," Obsérvese cómo la preocupación por ese estilo "genuinamente español" es común a aquella generación de intelectuales que contemplaron la pérdida de los últimos vestigios del imperio colonial español y comenzaron a preguntarse acer. ca de la esencia de España y de lo español.

14 Leopoldo Torres Balbás, ibid,, p. 246.

15 Fernando Chueca Goitia, Historia de la arquitectura española Edad Antigua y Edad Media, Madxid, 1965, p. 466. 
mudéjar, en esencia, es anticlásico. Por consiguiente, sólo existe una actitud mudéjar, un "metaestilo". 16 De esta manera, su crítica a Amador de los Ríos y Lampérez no tiene sentido ya que, por su parte, perpetúa la vieja tendencia al "casticismo". Chueca Goitia declara que sus intuiciones a la hora de escribir el libro Invariantes castizos de la arquitectura española ${ }^{17}$ tuvieron como fuente de inspiración al maestro Una-

16 Fernando Chueca Goitia, op. cit., p. 466. Después de la tesis de Chueca Goitia declarando que propiamente no es un estilo sino más bien un "metaestilo", la tenden" cia general ha sido seguir las ideas del gran historiador de la arquitedtura española 0 , a lo sumo, adoptar una postura ecléctica. Hasta ahora la revisión más completa del término es la de Gonzalo Borrás, "El mudéjar como constante artística", Actas del I Simposio Internacional de Mudejarismo, Madrid-Ternel, Diputación Provincial de Texuel - C. S. I. C., 1981, pp. 29-40, donde concluye calificando al mudéjar como "una constante artística del Irundo hispánico". En las mismas actas de dicho simposio, Santiago Sebastián publicó "Pervivencias hispanomusulmanas en Hispanoamérica" (pp. 509-16), donde afirma que "habria que calificax el fenómeno mutéjar como una moda o un arte, no un estilo, sino un subestilo, de un carácter netamente popular o popularista". No entendemos claramente cómo el fenómeno mudéjar pueda ser, al mismo tiempo, una moda o un arte; del mismo modo, no se comprende de qué manera, si no es un estilo, pueda ser, al propio tiempo, un subestilo. Esta tesis del arte mudéjlax como "perviveacia hispanomusulmana" fue expuesta también por Santiago Sebastián en "Revisión del concepto de mudejarismo", Formalismo e Iconografia, Churubusco, México, 1979, pp. 17-20. Asimismo, en la misma linea, José Guerrero Lovillo, Andalucia I, "Tierras de España", Publicaciones de la Fundación Juan March, p. 303: "No es propiamente un estilo, sino un proceso de pervivencia y convivencia." El capítulo titulado "El mudejarismo. Sus determinantes estilisticas" incide en caracterizarlo como un arte "genuinamente español", tal como lo califícaron Arnador de los Ríos, Menéndez y Pelayo, Gestoso, y posteriormente todos los eruditos adscritos a la "tradición eterna" unamuniana. Del mismo modo, los historiadores italianos podrían hablar de un arte "genuinamente italiano" o "genuinamente siciliano", según el gusto, al tratax del arte siculo-normando, por ejemplo. Otra rápida visión del concepto mudéjar, sin notas, puede veise en Gonzalo Borrás, Avte mudéjar aragonés, Zaragoza, 1978, pp. 13* 22; una recopilación de las interpretaciones sobre el arte mudéjar puede obtenerse en Maxía del Caimen Fraga González, Arquitectura mudéjar en la Baja Andalucia, Santa Cruz de Tenerife, 1977, pp. 17-34.

17 Fernando Chueca Goitia, Invariantes castizos de la arquitectura española, $2^{\mathrm{a}}$ ed., Seminarios y Ediciones, S. A., 1971, p. 10: "E1 imperio que, desde la más temprana juventud, había ejercido sobre mí el pensamiento de Unamuno, su poderosa personalidad, que en dos ocasiones inolvidables de mi vida había sentido de cerca, oyenido absorto sus palabras que me tenían suspendido y como en éxtasis, rebrotaron vigorosas cuando me atrevi a ir verciendo sobre el papel mis ideas confusas. Don Miguel de Una. muno fue mi guía y mi respaldo, pues, creyendo que mis pobres intuidiones tenían el aval del insigne maestro, me parecía edificar sobre tierra firme. Por eso, este librito es en el fondo tan unamuniano" "Por otra parte, podrá criticársenos que el discurso de Amador de los Ríos y la polémica sobre el "estilo mudéjax" son anteriores a la "genet" ración del 98". Sin embargo, en xealidad, el espíritu de la llamada "generación del 98" latía, por así decirlo, en el ambiente, con anterioridad a la derrota de 1898 . Desde 1855, Julián Sanz del Río, con sus ideas krausistas, había influido en los intelectuales 
muno. A la vista de esta afirmación no podemos encontrar más clara evidencia de esta tendencia nacionalista.

Si consideramos el estilo como la expresión y cualidad constante de un grupo, según lo define Meyer Schapiro, ${ }^{18}$ no hallamos un estilo mudéjar. No existen en el mudéjar norma ni estructura o diseño invariables. Existen más bien diferentes "manieras" en cada región. Cada una distinta de la otra, con diferentes plantas y alzados. No pueden ser codificadas. El arte mudéjar resulta algo adaptable y flexible que puede juntarse con el Románico, con el Gótico y con el Renacimiento. Por esta razón, Chueca Goitia señala que no tiene las características de una escuela. 19 No existe, pues, una escuela, sino tantas escuelas como lugares donde se encuentre el arte mudéjar.

El arte mudéjar más que un estilo o metaestilo es sencillamente influencia islámica en el arte español. El arte mudéjar no es la expresión de un grupo por él mismo; es más bien la expresión de un grupo por otro: sus clientes. Este grupo tiene distinta mentalidad, diferente religión. Además, los mudéjares estaban sometidos a los cristianos, con todo lo que ello implica; no les estaba permitido construir nuevas mezquitas y sólo podían usar las antiguas. Incluso su pobre literatura, la llamada literatura "aljamiada", ${ }^{20}$ un dialecto español escrito en árabe, estaba prohibida, oculta, escondida. Después de la rebelión de 1264, muchos de ellos fueron esclavos. Más tarde, en los siglos XIV y xv, algunos de ellos se convirtieron al cristianismo, pero sin perder sus propias identidades.

Los mudéjares, aun teniendo una conciencia de grupo, no fueron libres de expresar su propia Weltanschaung. Sus creaciones y sus obras estaban sometidas a la ley cristiana. Su obra estaba destinada a seguir y a coexistir con la obra cristiana. De este modo, resulta algo muy distinto a la más liberada vida de su hermano, el arte mozárabe. Consecuentemente, no podemos permitirnos continuar defendiendo la existencia de un estilo mudéjar, pues parece, más bien, haber sido la expresión de cierto "casticismo" español.

españoles que, después de 1880, y sobre todo, con Francisco Giner de Ios Ríos se consagraron a la renovación de España. En este sentido vid. Pierte Vilar, Historia de España, Librairie Espagnole, Paris, 1975, p. 109. Ciertamente, la continuidad de esta tendencia "castiza" dentro de la historiografía artística española no es más que la expresión de la gran crisis de la sociedad española del siglo $\mathbf{x x}$, que tiene sus orígenes en los problemas planteados en la segunda mitad del siglo xix y aún no resueltos.

18 Meyer Shapiro, "Style", in Anthropology Today, Chicago, 1959, p. 287.

19 Fernando Chueca Goitia, Historia de la arquitectura..., p. 466.

20 Georgina Goddard King, op. cit. 